\title{
Population pharmacokinetics and pharmacogenomics of tacrolimus in Chinese children receiving a liver transplant: initial dose recommendation
}

\author{
Xiao Chen ${ }^{1 \#}$, Dong-Dong Wang ${ }^{1 \#}$, Hong $\mathrm{Xu}^{2}$, Zhi-Ping $\mathrm{Li}^{1}$ \\ ${ }^{1}$ Department of Pharmacy, Children's Hospital of Fudan University, Shanghai, China; ${ }^{2}$ Department of Nephrology, Children's Hospital of Fudan \\ University, Shanghai, China \\ Contributions: (I) Conception and design: All authors; (II) Administrative support: H Xu, ZP Li; (III) Provision of study materials or patients: X Chen, \\ DD Wang; (IV) Collection and assembly of data: X Chen, DD Wang; (V) Data analysis and interpretation: X Chen, DD Wang; (VI) Manuscript \\ writing: All authors; (VII) Final approval of manuscript: All authors. \\ \#These authors contributed equally to this work and are co-first authors. \\ Correspondence to: Hong Xu; Zhi-Ping Li. Children's Hospital of Fudan University, 399, Wanyuan Road, Shanghai, China. \\ Email: hxu@shmu.edu.cn; zpli@fudan.edu.cn.
}

Background: In order to improve the precision of treatment with tacrolimus in Chinese patients undergoing pediatric liver transplantation, the optimum initial dose of tacrolimus was determined based on population pharmacokinetics and pharmacogenomics.

Methods: Demographic data, clinical parameters, drug combinations and pharmacogenomics were integrated to build a population pharmacokinetic model using NONMEM. Additionally, Monte Carlo simulations were used to optimize the recommended initial dose.

Results: Weight, patient cytochrome $4503 \mathrm{~A}(C Y P 3 A) 5$ genotype, and co-administration with wuzhicapsule $(\mathrm{WZ})$ were incorporated into the final model. For children with a $C Y P 3 A 5^{*} 3 /^{*} 3$ genotype not co-administered WZ, $0.10 \mathrm{mg} / \mathrm{kg} /$ day split into two doses was recommended for patients weighing $5-17 \mathrm{~kg}$, and $0.05 \mathrm{mg} / \mathrm{kg} /$ day split into two doses was recommended for patients weighing $17-60 \mathrm{~kg}$. For children with a $C Y P 3 A 5^{*} 1$ allele not co-administered $W Z, 0.25 \mathrm{mg} / \mathrm{kg} /$ day for patients weighing $5-10 \mathrm{~kg}$, $0.20 \mathrm{mg} / \mathrm{kg} /$ day for patients weighing $10-17 \mathrm{~kg}, 0.15 \mathrm{mg} / \mathrm{kg} /$ day for patients weighing $17-36 \mathrm{~kg}$, and $0.10 \mathrm{mg} / \mathrm{kg} /$ day for patients weighing $36-60 \mathrm{~kg}$; all split into two doses was recommended. For children with a $C Y P 3 A 5^{*} 3 /^{*} 3$ genotype co-administered $W Z, 0.10 \mathrm{mg} / \mathrm{kg} /$ day for patients weighing $5-11 \mathrm{~kg}$, and $0.05 \mathrm{mg} / \mathrm{kg} / \mathrm{day}$ for patients weighing $11-60 \mathrm{~kg}$; both split into two doses was recommended. For children with a $C Y P 3 A 5^{*} 1$ allele who were co-administered $W Z, 0.20 \mathrm{mg} / \mathrm{kg} /$ day for patients weighing $5-10 \mathrm{~kg}$, $0.15 \mathrm{mg} / \mathrm{kg} /$ day for patients weighing $10-22 \mathrm{~kg}$, and $0.10 \mathrm{mg} / \mathrm{kg} /$ day for patients weighing 22-60 kg all split into two doses was recommended.

Conclusions: The optimal initial dose of tacrolimus was determined based on population pharmacokinetics and pharmacogenomics in Chinese patients undergoing pediatric liver transplantation.

Keywords: Initial dose recommendation; pediatric liver transplantation; pharmacogenomics; population pharmacokinetics; tacrolimus

Submitted Mar 03, 2020. Accepted for publication Sep 10, 2020.

doi: $10.21037 / \mathrm{tp}-20-84$

View this article at: http://dx.doi.org/10.21037/tp-20-84 


\section{Introduction}

Tacrolimus is a macrolide produced by Streptomyces tsukubaensis, and is a powerful immunosuppressant that was first discovered in 1984 when seeking novel anti-cancer and immunosuppressive drugs (1). Since 1994, tacrolimus has been approved as a prophylactic for organ rejection following a liver transplant in the United States (1). At present, in addition to preventing graft rejection during renal transplant (2), heart transplant (3), lung transplant (4), hematopoietic stem cell transplant (5) and other types of transplants, tacrolimus has also been used to treat a variety of diseases, which include systemic onset juvenile idiopathic arthritis (6), nephrotic syndrome (7), myasthenia gravis (8), ulcerative colitis (9), systemic lupus erythematosus (10), lupus nephritis (11) and autoimmune hepatitis (12). However, with a narrow treatment window and considerable pharmacokinetic variability between individuals, it is difficult to determine the optimal tacrolimus concentration within the window of treatment (13). Furthermore, low concentrations of tacrolimus can increase the risk of rejection, whereas high concentration can lead to adverse reactions, including nephrotoxicity, neurotoxicity, infection, nausea, tumors, diabetes and gastrointestinal reactions $(1,14)$. Therefore, in clinical practice, subsequent doses are usually adjusted according to the range of the treatment window combined with therapeutic drug monitoring (TDM). However, determining the optimal initial dose remains difficult as there is no previous TDM concentration for comparison. In clinical practice, the initial dose is based on the drug instructions and the experience of physicians and pharmacists; however, this frequently results in a suboptimal initial dose.

Fortunately, population pharmacokinetic models and Monte Carlo simulation can be used to assist in optimizing the initial dosage $(15,16)$. Since the initial clinical use of tacrolimus, several population pharmacokinetics models based on patients receiving a liver transplant have been built (17-22). However, the precise treatment of tacrolimus and a model for the recommended initial dose in Chinese patients undergoing pediatric liver transplants has not been determined. Thus, the present study built a model to determine the initial dose of tacrolimus for Chinese patients undergoing pediatric liver transplantation based on population pharmacokinetics and pharmacogenomics. We present the following article in accordance with the TRIPOD reporting checklist (available at http://dx.doi. org/10.21037/tp-20-84).

\section{Methods}

\section{Patients}

Data on Chinese children who underwent a liver transplant and were treated with tacrolimus between September 2014 and October 2019 at the Children's Hospital of Fudan University were collected retrospectively. Partial basic clinical data of children were gathered from previous studies $(23,24)$. The present study was conducted in accordance with the Declaration of Helsinki (2013 revision) and was approved by the Ethics Committee of the Children's Hospital of Fudan University (Ethical code: [2019] 020). Demographic data of patients and drug combinations were collected. The present study was performed retrospectively, and only used leftover or discarded specimens. Therefore, the need for written informed consent was waived by the Ethics Committee of Children's Hospital of Fudan University.

\section{TDM and pharmacogenomic analysis}

Tacrolimus concentration was tested using the Emit ${ }^{\circledR}$ 2000 Tacrolimus Assay (Siemens Healthcare Diagnostics Inc., Newark, NJ, USA) with a range of $2.0-30 \mathrm{ng} / \mathrm{mL}$. Pharmacogenomic analysis was performed using TDM residual blood samples, which was measured by Admera Health using a $\mathrm{PGxOne}{ }^{\circledR} 160$ via the Illumina X10 Sequencing System. Hardy-Weinberg Equilibrium was determined using STATA version 12.0 (Stata Corp., LP., USA). $\mathrm{P}<0.05$ was considered to indicate a statistically significant difference.

\section{Population pharmacokinetic model}

The non-linear mixed-effects modeling software, NONMEM (Edition 7; ICON Development Solutions, Ellicott City, MD, USA) and a first-order conditional estimation method with interaction (FOCE-I method) were used to build the model. The pharmacokinetic parameters covered CL/F, V/F, and Ka. The value of Ka was fixed to $4.48 / \mathrm{h}(23,25)$.

\section{Random effects model}

Inter-individual variabilities were estimated using Eq. [1]:

$$
C_{i}=T V(C) \times \exp \left(\eta_{\mathrm{i}}\right)
$$

$C_{i}$ represents individual parameters and $T V(C)$ represents 
typical individual parameters. $\eta_{\mathrm{i}}$ was the symmetrical distribution, which was a random term with zero mean and variance $\omega^{2}$.

Random residual variabilities were estimated using Eq. [2]:

$$
C_{i}=C_{\text {prei }} \times\left(1+\varepsilon_{1}\right)+\varepsilon_{2}
$$

$C_{i}$ were the observed concentrations, $C_{\text {prei }}$ were the individual predicted concentrations and $\varepsilon_{1}$ and $\varepsilon_{2}$ were symmetrical distributions, which was a random term with zero mean and variance $\sigma_{2}$.

\section{Covariate model}

Pharmacokinetic parameters and weight were evaluated using Eq. [3]:

$$
C_{i}=C_{\text {std }} \times\left(W_{i} / W_{\text {std }}\right)^{\text {POWER }}
$$

$C_{i}$ represents the $\mathrm{i}^{\text {th }}$ individual parameters, $W_{i}$ represents the $\mathrm{i}^{\text {th }}$ individual weight. $W_{\text {std }}$ represents the standard weight of $70 \mathrm{~kg}$. $C_{\text {std }}$ was the typical individual parameter. POWER was the allometric coefficient: 0.75 for the CL/F and 1 for the V/F (26).

Pharmacokinetic parameters and genotypes were evaluated using Eq. [4].

$$
C_{i}=T V(C) \times \theta^{\text {genotype }}
$$

Pharmacokinetic parameters and the other continuous covariates or categorical covariates were described with Eqs. [5] and [6], respectively.

$$
\begin{aligned}
& C_{i}=T V(C) \times\left(\operatorname{Cov}_{i} / \operatorname{Cov}_{\text {median }}\right) \theta \\
& C_{i}=T V(C) \times\left(1+\theta \times \operatorname{Cov}_{i}\right)
\end{aligned}
$$

where $C_{i}$ represents individual parameters, $T V(C)$ represents typical individual parameters. $\theta$ represents the parameter which was assessed and $\operatorname{Cov}_{i}$ represents the covariate of the $\mathrm{i}^{\text {th }}$ individual. Cov $_{\text {median }}$ represents the populations median value.

\section{Statistical analysis}

Changes of objective function value (OFV) were calculated via covariate inclusions. An OFV decrease of $>3.84\left(\chi^{2}\right.$, $\alpha=0.05$, d.f. $=1$ ) was used as a standard for inclusion. When a full regression model was built, the model was tested by excluding these covariates from each parameter individually. An OFV increase $>6.63\left(\chi^{2}, \alpha=0.01\right.$, d.f. $\left.=1\right)$ was used as a standard for retention.

\section{Model evaluation}

The final model was estimated using goodness-of-fit plots (observations $v s$. population predictions, observations $v s$. individual predictions, conditional weighted residuals $v s$. population predictions, and conditional weighted residuals $v s$. time after the start of therapy) and a bootstrap method $(\mathrm{n}=1,000)$.

\section{Simulation}

The effect of the initial dose on the probability of achieving the target concentrations $(5-20 \mathrm{ng} / \mathrm{mL})$ was studied using Monte Carlo simulations based on the final model. The simulation included four scenarios, (I) recipients with cytochrome $4503 \mathrm{~A}($ CYP3A) $5 * 3 / * 3$ and not co-administered WZ, (II) recipients with a $C Y P 3 A 5^{*} 1$ allele $\left(C Y P 3 A 5^{*} 1{ }^{*} 1\right.$ and $C Y P 3 A 5^{*} 11^{*} 3$ ) not co-administered WZ, (III) recipients with $C Y P 3 A 5^{*} 3 / * 3$ co-administered $\mathrm{WZ}$, and (IV) recipients with a $C Y P 3 A 5^{*} 1$ allele co-administered WZ. In each case, 7 weight groups $(5,10,20,30,40,50$ and $60 \mathrm{~kg})$ and nine doses $(0.01,0.05,0.10,0.15,0.20,0.25,0.30,0.35$ and $0.40 \mathrm{mg} / \mathrm{kg} /$ day) were simulated 1,000 times each.

\section{Results}

\section{Patient information}

Data on 12 Chinese patients who underwent pediatric liver transplantation, including 8 boys and 4 girls, age range from $0.47-7.96$ years was used in the present study. Demographic data of patients and drug combinations are shown in Table 1. Partial basic clinical data of some children were gathered from previous studies $(23,24)$. Pharmacogenetics data as well as the Hardy-Weinberg equilibrium test results are shown in Table 2. Pearson $\chi^{2}$-test $\mathrm{P}>0.05$, showing HardyWeinberg equilibrium of genotypes from the present study were representative of the general population.

\section{Modeling}

The final population pharmacokinetic models were as follows:

$$
\begin{aligned}
& \mathrm{CL} / \mathrm{F}=6.57 \times(\mathrm{WT} / 70)^{0.75} \times 1.61^{\mathrm{CYP} 3 \mathrm{~A} 5} \times(1-0.108 \times \mathrm{WZ}) \\
& \mathrm{V} / \mathrm{F}=77.6 \times(\mathrm{WT} / 70)
\end{aligned}
$$


Table 1 Demographic data of patients and drug combination ( $\mathrm{n}=12)$

\begin{tabular}{|c|c|c|}
\hline Characteristic & Mean \pm SD & Median (range) \\
\hline Age (years) & $3.11 \pm 2.28$ & $2.42(0.47-7.96)$ \\
\hline Weight (kg) & $13.79 \pm 5.12$ & $13.00(6.40-28.00)$ \\
\hline Post-transplantation day (days) & $253.00 \pm 340.00$ & $121.00(4.00-1,877.00)$ \\
\hline Alanine transaminase (IU/L) & $49.28 \pm 58.61$ & $26.00(9.00-417.00)$ \\
\hline Aspartate transaminase (IU/L) & $49.18 \pm 45.36$ & $34.00(13.00-288.00)$ \\
\hline Creatinine $(\mu \mathrm{mol} / \mathrm{L})$ & $25.72 \pm 11.78$ & $22.00(7.00-82.00)$ \\
\hline Urea (mmol/L) & $4.52 \pm 1.87$ & $4.20(0.70-12.60)$ \\
\hline Direct bilirubin $(\mu \mathrm{mol} / \mathrm{L})$ & $9.12 \pm 27.08$ & $3.25(1.00-226.70)$ \\
\hline Total bilirubin $(\mu \mathrm{mol} / \mathrm{L})$ & $19.22 \pm 39.60$ & $11.10(2.80-330.80)$ \\
\hline Hematocrit (\%) & $32.83 \pm 4.95$ & $33.71(15.84-43.30)$ \\
\hline Hemoglobin (g/L) & $107.19 \pm 18.34$ & $110.00(49.00-149.00)$ \\
\hline Mean corpuscular hemoglobin (pg) & $27.33 \pm 23.40$ & $25.80(16.10-312.00)$ \\
\hline Mean corpuscular hemoglobin concentration $(\mathrm{g} / \mathrm{L})$ & $325.73 \pm 18.01$ & $325.00(258.00-371.00)$ \\
\hline \multicolumn{3}{|l|}{ Number of co-medications } \\
\hline Glucocorticoid & \multicolumn{2}{|r|}{11} \\
\hline
\end{tabular}

Where WT, CYP3A5, and WZ represents weight, recipient $C Y P 3 A 5$ genotype, and co-administration of $\mathrm{WZ}$, respectively. For patients who were $C Y P 3 A 5^{*} 3 /^{*} 3$, the $C Y P 3 A 5$ value $=0$; for patients with a $C Y P 3 A 5^{*} 1$ allele, the CYP $3 A 5$ value $=1$; and for patients co-administered $W Z$, the $W Z$ value $=1$, otherwise $W Z$ value $=0$.

\section{Validation}

Figure 1 shows goodness-of-fit plots from the final model and Table 3 shows the final model parameter estimates and bootstrap validation. The bootstrap median values were similar to the final model estimated values. Therefore, we can see that the final model was dependable.

\section{Initial dose recommendation}

As shown in Figure 2, under the same weight, tacrolimus clearance was different in recipients with a $C Y P 3 A 5 * 3 / * 3$ genotype not co-administered $W Z$, recipients with a CYP $3 A 5^{*} 1$ allele not co-administered $\mathrm{WZ}$, recipients with a CYP $3 A 5^{*} 3{ }^{*} 3$ genotype co-administered $\mathrm{WZ}$, and recipients with a $C Y P 3 A 5^{*} 1$ allele co-administered $\mathrm{WZ}$; their clearance ratios were 1:1.61:0.892:1.43612, respectively. Using Monte Carlo simulations, the initial dose recommendation of tacrolimus with different cases were simulated, the results of which are shown in Figure 3 and Table 4. For children with a $C Y P 3 A 5^{*} 3 / * 3$ genotype not co-administered $\mathrm{WZ}$, $0.10 \mathrm{mg} / \mathrm{kg} /$ day split into two doses was recommended for 
Table 2 Pharmacogenetics analysis and Hardy-Weinberg equilibrium

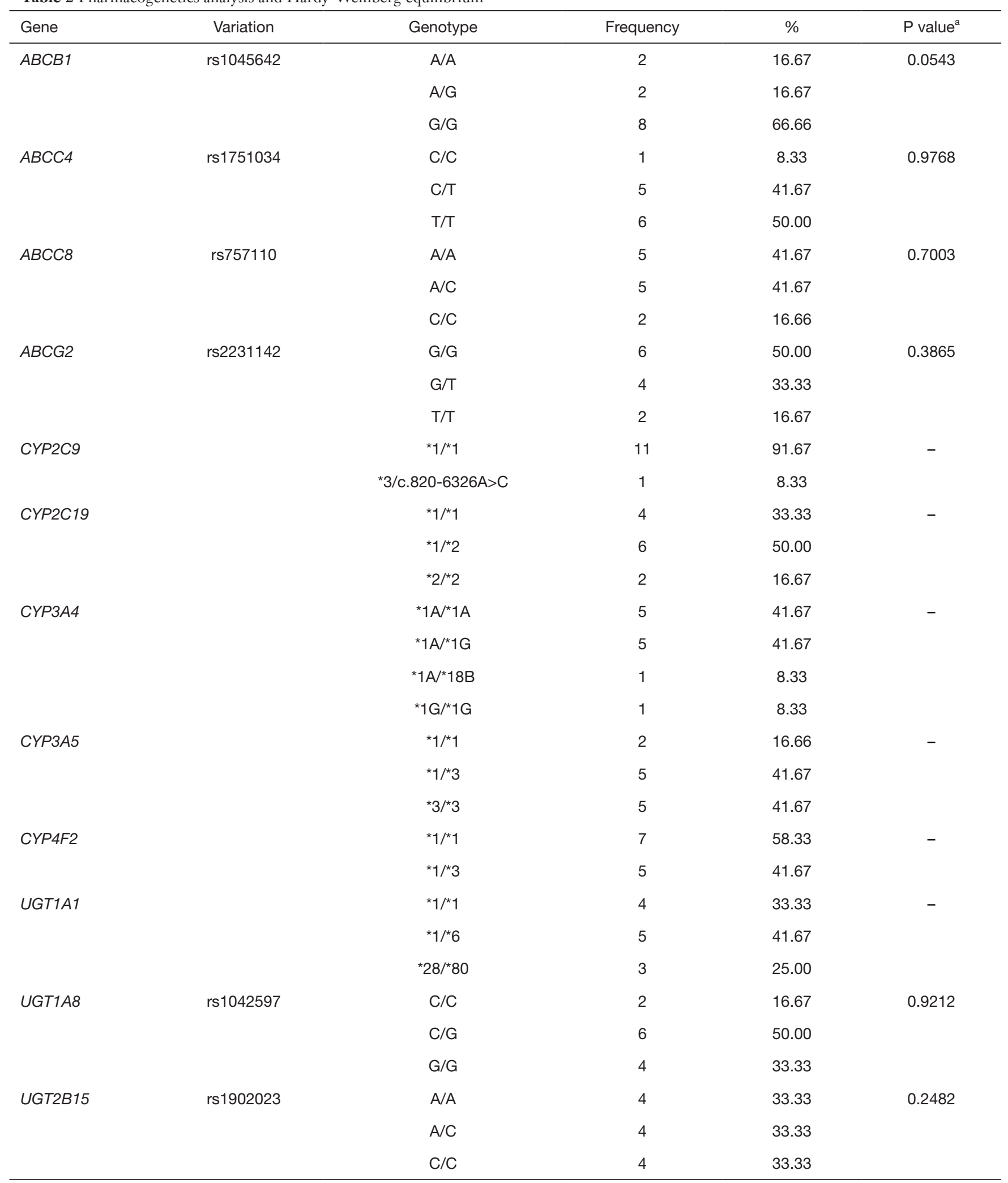

\footnotetext{
${ }^{\mathrm{a}}$, Pearson chi-squared test.
} 

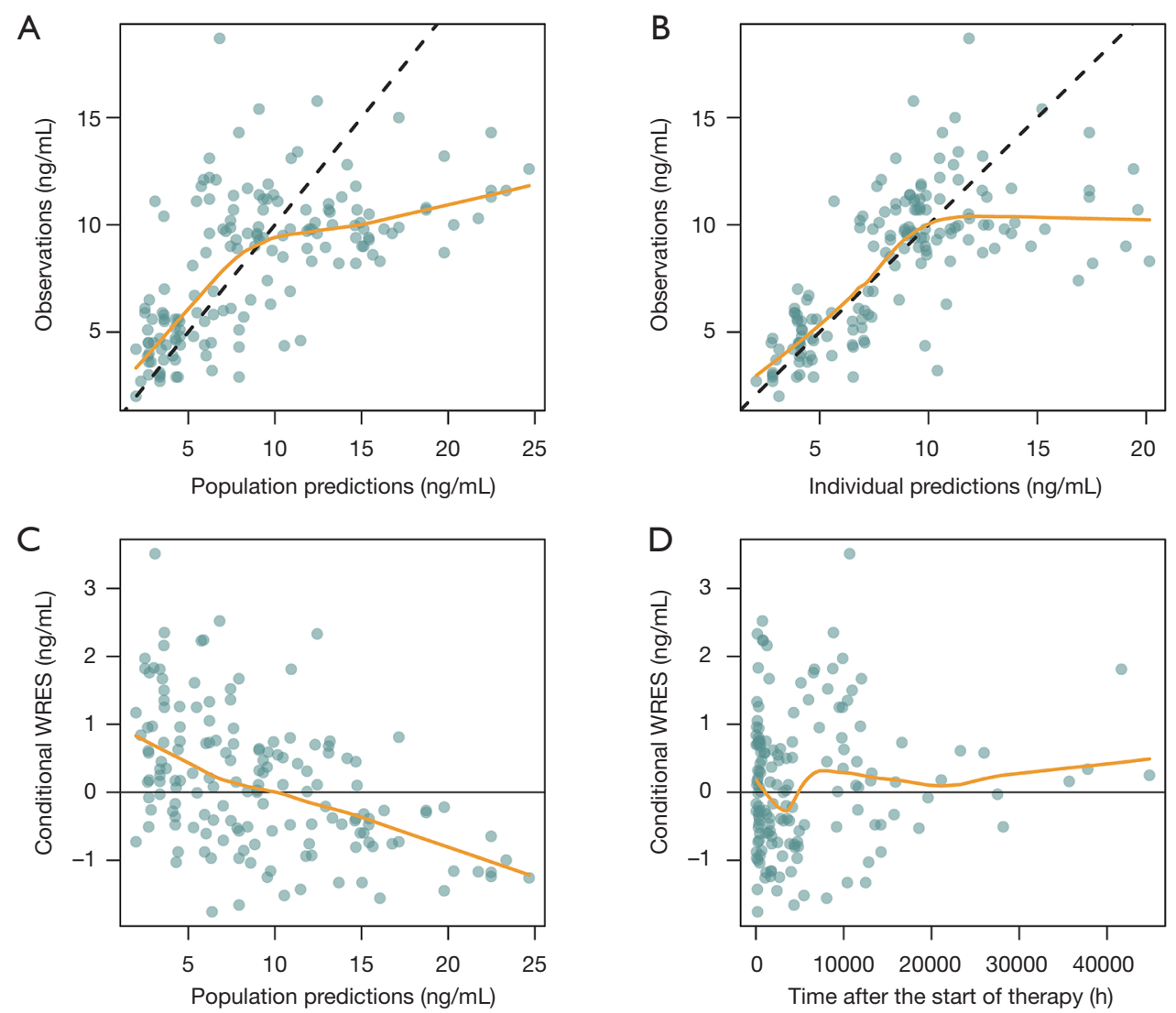

Figure 1 Goodness-of-fit plots from the final population model. (A) Observations vs. population predictions; (B) observations vs. individual predictions; (C) conditional WRES vs. population predictions; (D) conditional WRES vs. time after the start of therapy. Partial concentration values were collected in previous studies $(23,24)$. WRES, weighted residuals.

Table 3 Parameter estimates of final model and bootstrap validation

\begin{tabular}{|c|c|c|c|c|c|}
\hline Parameter & Estimate & SE & \multicolumn{2}{|c|}{ Bootstrap } & Bias (\%) \\
\hline $\mathrm{CL} / \mathrm{F}(\mathrm{L} / \mathrm{h})$ & 6.57 & 0.414 & 6.57 & $(2.91,9.10)$ & 0 \\
\hline V/F (L) & 77.6 & 1.198 & 71.4 & $(15.6,501.9)$ & -7.99 \\
\hline $\mathrm{Ka}\left(\mathrm{h}^{-1}\right)$ & 4.48 (fixed) & - & - & - & - \\
\hline$\theta_{\mathrm{wz}}$ & -0.108 & 0.615 & -0.095 & $(-0.210,-0.003)$ & -12.04 \\
\hline$\omega_{\mathrm{V} / \mathrm{F}}$ & 0.396 & 0.818 & 0.318 & $(0.088,1.039)$ & -19.70 \\
\hline$\sigma_{1}$ & 0.288 & 0.137 & 0.274 & $(0.185,0.318)$ & -4.86 \\
\hline$\sigma_{2}$ & 0.720 & 0.697 & 0.836 & $(0.241,1.471)$ & 16.11 \\
\hline
\end{tabular}

$90 \%$ confidential interval was displayed as the 5th, 95th percentile of bootstrap estimates. CL/F, apparent oral clearance (L/h); V/F, apparent volume of distribution $(\mathrm{L})$; Ka, absorption rate constant $\left(\mathrm{h}^{-1}\right) ; \theta_{\text {CYP3A5 }}$ was the coefficient of CYP3A5 genotype; $\theta_{\mathrm{WZ}}$ was the coefficient of the wuzhi-capsule; $\omega_{\mathrm{V} / \mathrm{F}}$, inter-individual variability of $\mathrm{V} / \mathrm{F} ; \sigma_{1}$, residual variability, proportional error; $\sigma_{2}$, residual variability, additive error; Bias, prediction error, Bias $=($ Median - Estimate $) /$ Estimate $\times 100 \%$. 


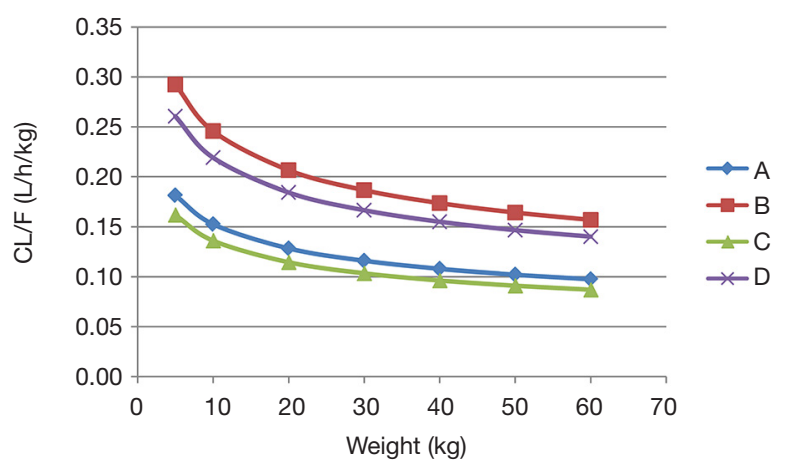

Figure $2 \mathrm{CL} / \mathrm{F}$ of tacrolimus in patients undergoing pediatric liver transplant. (A) $C Y P 3 A 5^{*} 3 /^{*} 3$ recipients who were not coadministered $\mathrm{WZ}$; (B) recipients with a $C Y P 3 A 5^{*} 1$ allele who were not co-administered $\mathrm{WZ}$; (C) $C Y P 3 A 5^{*} 3{ }^{*} 3$ co-administered $\mathrm{WZ}$; (D) recipients with a $C Y P 3 A 5^{*} 1$ allele co-administered $\mathrm{WZ}$. WZ, wuzhi-capsule.

A

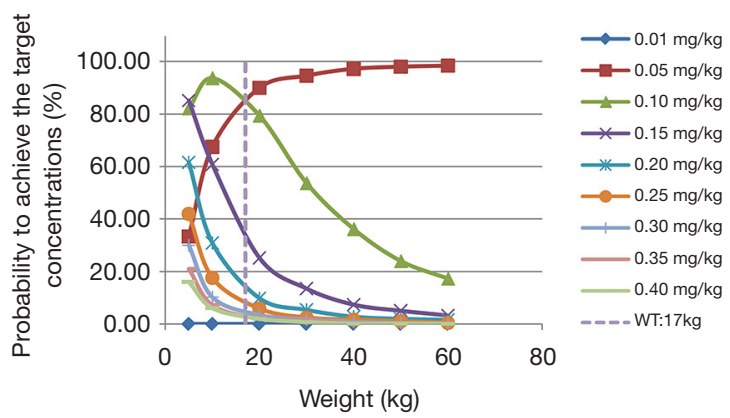

C

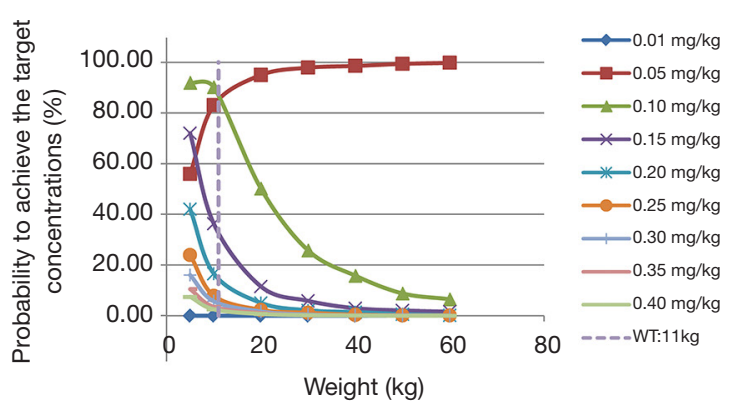

patients weighing $5-17 \mathrm{~kg}$, and $0.05 \mathrm{mg} / \mathrm{kg} /$ day split into two doses was recommended for patients weighing $17-60 \mathrm{~kg}$. For children with a $C Y P 3 A 5^{*} 1$ allele not co-administered WZ, $0.25 \mathrm{mg} / \mathrm{kg} /$ day for patients weighing $5-10 \mathrm{~kg}$, $0.20 \mathrm{mg} / \mathrm{kg} / \mathrm{day}$ for patients weighing $10-17 \mathrm{~kg}$, $0.15 \mathrm{mg} / \mathrm{kg} /$ day for patients weighing $17-36 \mathrm{~kg}$, and $0.10 \mathrm{mg} / \mathrm{kg} /$ day for patients weighing $36-60 \mathrm{~kg}$; all split into two doses was recommended. For children with a $C Y P 3 A 5^{*} 3 /^{*} 3$ genotype co-administered $\mathrm{WZ}$, $0.10 \mathrm{mg} / \mathrm{kg} / \mathrm{day}$ for patients weighing $5-11 \mathrm{~kg}$, and $0.05 \mathrm{mg} / \mathrm{kg} /$ day for patients weighing 11-60 kg; both split into two doses was recommended. For children with a CYP $3 A 5^{*} 1$ allele and co-administered $\mathrm{WZ}, 0.20 \mathrm{mg} / \mathrm{kg} / \mathrm{day}$ for patients weighing $5-10 \mathrm{~kg}, 0.15 \mathrm{mg} / \mathrm{kg} / \mathrm{day}$ for patients weighing $10-22 \mathrm{~kg}$, and $0.10 \mathrm{mg} / \mathrm{kg} / \mathrm{day}$ for patients weighing 22-60 kg all split into two doses was recommended.

B

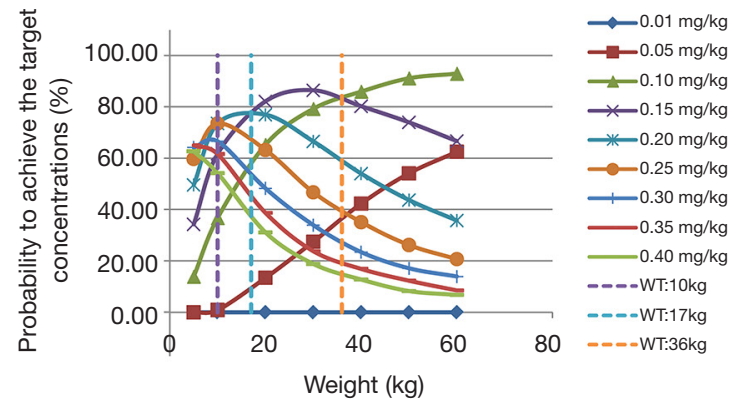

D

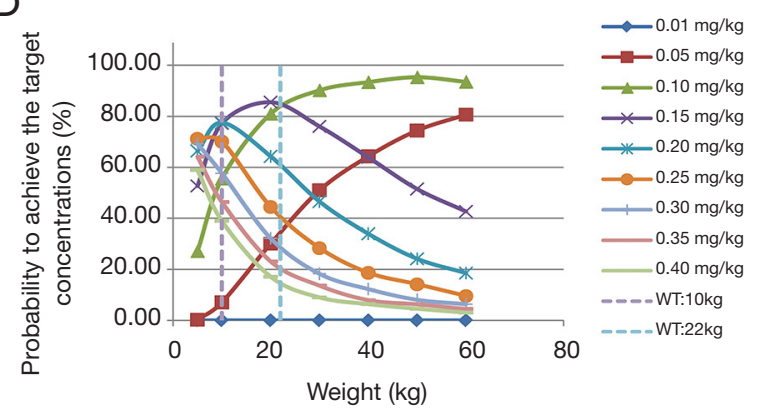

Figure 3 Probability of achieving the target concentrations. (A) CYP3A5*3/*3 recipients who were not co-administered WZ; (B) recipients with a $C Y P 3 A 5^{*} 1$ allele who were not co-administered $\mathrm{WZ}$; (C) $C Y P 3 A 5^{*} 3{ }^{*} 3$ recipients co-administered $\mathrm{WZ}$; (D) recipients with a CYP3A5*1 allele co-administered WZ. WZ, wuzhi-capsule. 
Table 4 Initial dosage recommendation of tacrolimus in paediatric liver transplant

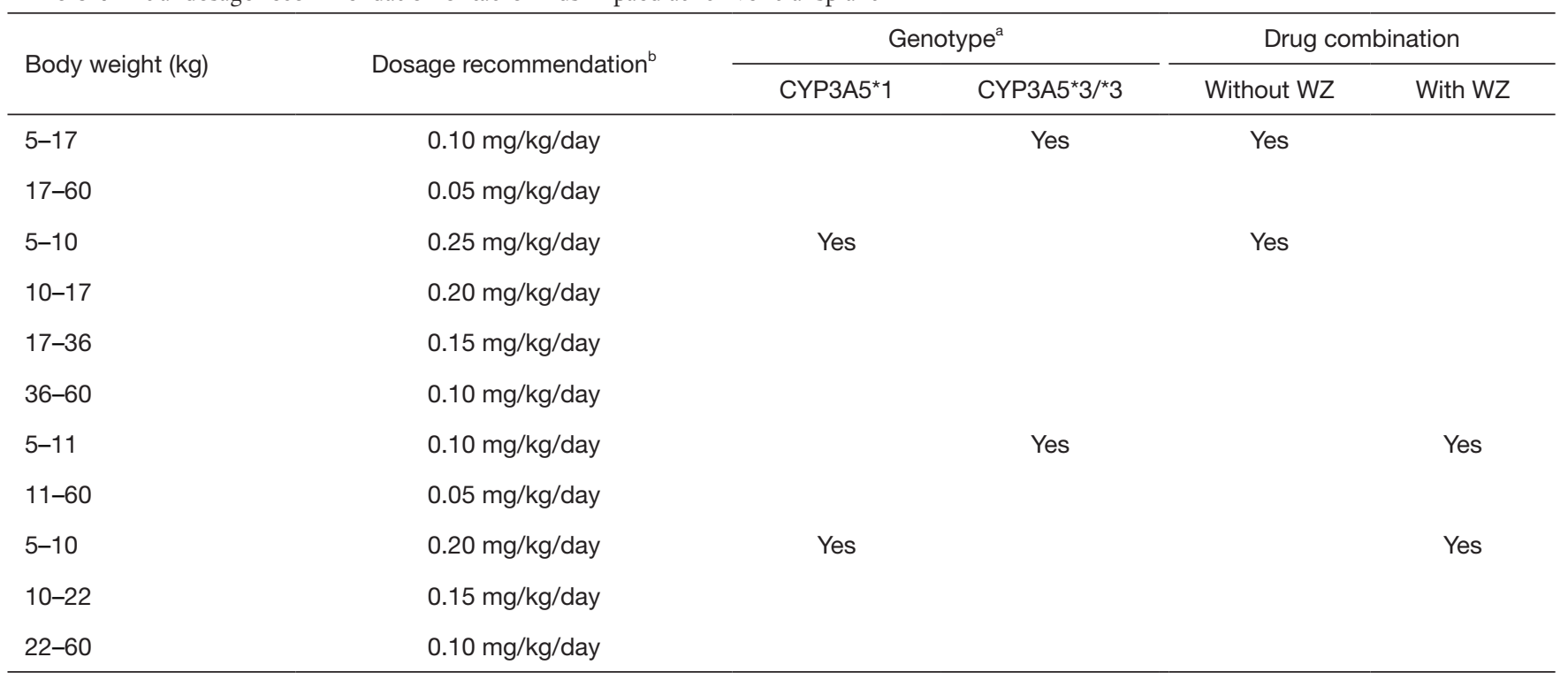

a , recipient; ${ }^{b}$, splited into two doses; $C Y P 3 A 5^{\star} 1, C Y P 3 A 5^{*} 1{ }^{*} 1$ and $C Y P 3 A 5^{\star} 1{ }^{*} 3$; WZ, wuzhi-capsule.

\section{Discussion}

Tacrolimus exhibits low oral bioavailability (10-20\%), but this varies notably between individuals, due to intestinal P-glycoprotein efflux and intestinal and hepatic CYP3Amediated metabolism (27). Human CYP3A is present in at least two heterogeneous expression isoforms, CYP3A4 and CYP3A5, of which, CYP3A5 is the most important metabolic enzyme with regard to tacrolimus (28).

At present, several tacrolimus population pharmacokinetic models based on Chinese patients undergoing pediatric liver transplant have been established $(23,25)$. For example, in Yang et al., a tacrolimus population pharmacokinetic model was developed in Chinese children with early after liver transplantation (25). In this previous study, their goal was to model external predictiveness and set up a novel population pharmacokinetic model which was applicable to a traditional TDM datasets (23). The model from a previous publication was deemed inadequate when used with real-world datasets, and thus a new population pharmacokinetic model, which was applicable to real-world datasets was produced (23). However, neither of the above tacrolimus population pharmacokinetics studies in Chinese patients undergoing pediatric liver transplants considered the effect of genotype, which may result in considerable uncertainty and introduce deviations to the initial dosage optimization model. Thus, in the present study, population pharmacokinetics and pharmacogenomics were combined to achieve accurate initial dose recommendation in for Chinese patients undergoing pediatric liver transplants.

In our study, weight, CYP $3 A 5$ genotype, and coadministration with $\mathrm{WZ}$ were incorporated into the final model. It has been shown that a Chinese medicine, WZ, which includes schisantherin A, schisandrol B and schisandrin (29), has a notable effect on tacrolimus and can increase the effective tacrolimus concentration (30-32) by inhibiting CYP3A which metabolizes tacrolimus $(32,33)$. Thus, WZ can be used to reduce the tacrolimus dose and save money on health care, especially for children who need tacrolimus long term (34), such as children with liver transplants.

In addition, the present study found that under the same weight, tacrolimus clearance differed between $C Y P 3 A 5^{*} 3 / * 3$ patients not co-administered WZ, patients with a CYP $3 A 5^{*} 1$ allele not co-administered WZ, CYP $3 A 5^{*} 3{ }^{*} 3$ patients co-administered $\mathrm{WZ}$ and patients with a $C Y P 3 A 5^{*} 1$ allele co-administered $\mathrm{WZ}$; the clearance ratios were 1:1.61:0.892:1.43612, respectively. Furthermore, based on simulations using the established model; for $C Y P 3 A 5^{* 3} / * 3$ patients not co-administered $\mathrm{WZ}, 0.10 \mathrm{mg} / \mathrm{kg} /$ day split into two doses was recommended for patients weighing $5-17 \mathrm{~kg}$, and $0.05 \mathrm{mg} / \mathrm{kg} / \mathrm{day}$ split into two doses was recommended for patients weighing $17-60 \mathrm{~kg}$. For children with a CYP $3 A 5^{*} 1$ allele not co-administered $\mathrm{WZ}, 0.25 \mathrm{mg} / \mathrm{kg} /$ day 


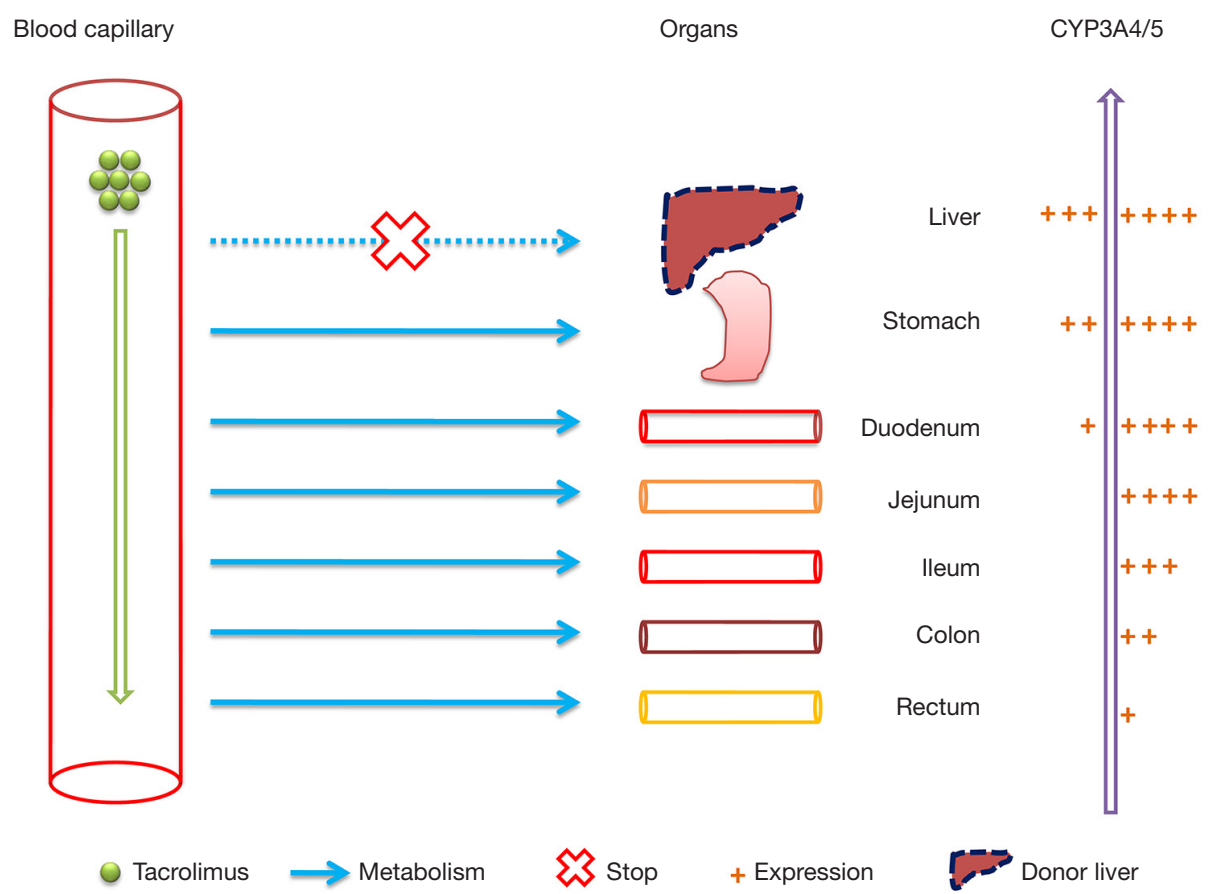

Figure 4 Metabolism of the initial dose of tacrolimus. Expression of CYP3A4/5 from the rectum, colon, ileum, jejunum, duodenum, to the stomach gradually increases (1).

for patients weighing $5-10 \mathrm{~kg}, 0.20 \mathrm{mg} / \mathrm{kg} /$ day for patients weighing $10-17 \mathrm{~kg}, 0.15 \mathrm{mg} / \mathrm{kg} / \mathrm{day}$ for patients weighing $17-36 \mathrm{~kg}$, and $0.10 \mathrm{mg} / \mathrm{kg} /$ day for patients weighing $36-60 \mathrm{~kg}$; all split into two doses was recommended. For children with a CYP $3 A 5^{*} 3 / * 3$ genotype co-administered WZ, $0.10 \mathrm{mg} / \mathrm{kg} /$ day for patients weighing $5-11 \mathrm{~kg}$, and $0.05 \mathrm{mg} / \mathrm{kg} /$ day for patients weighing $11-60 \mathrm{~kg}$; both split into two doses was recommended. For children with a CYP3A5*1 allele co-administered WZ, $0.20 \mathrm{mg} / \mathrm{kg} / \mathrm{day}$ for patients weighing $5-10 \mathrm{~kg}, 0.15 \mathrm{mg} / \mathrm{kg} /$ day for patients weighing $10-22 \mathrm{~kg}$, and $0.10 \mathrm{mg} / \mathrm{kg} /$ day for patients weighing $22-60 \mathrm{~kg}$ all split into two doses was recommended.

A novel discovery of the present study was that compared with tacrolimus clearance previously reported in Chinese patients with pediatric refractory nephritic syndrome patients (not receiving a liver transplant) (34), the clearance of tacrolimus was markedly reduced in the early stage of the liver transplant in Chinese children. This was primarily due to the limited function of the transplanted liver in the short period of time whilst still in the setting up stage, particularly in the early stage of administration of the initial dose, thus the metabolism of tacrolimus in the transplanted liver was insufficient. We hypothesize that the initial dose after transplantation is primarily metabolized by the intestine, which also explains why donor liver genotypes can be ignored when determining the initial dose, as shown in Figure 4. This also confirmed that although we did not consider donor liver genotypes, the recommended initial dose was still suitable.

However, there were limitations in the present study. This study is a single-center study and the number of patients was limited. Thus additional data from other sources are needed to verify the validity of our model.

\section{Conclusions}

The optimal initial dose of tacrolimus for Chinese patients undergoing pediatric liver transplantation was determined based on population pharmacokinetics and pharmacogenomics, for the first time.

\section{Acknowledgments}

Funding: This study was supported by grants from the Important Weak Subject Construction Project of Shanghai 
(grant No. 2016ZB0305), Clinical Pharmacy Key Specialty Construction Project of Shanghai (grant No. 2017/26), Scientific Research Project of Science and Technology Commission of Shanghai Municipality (grant Nos. 18DZ1910604/19DZ1910703), Shanghai Science and Technology Commission (grant No. 19XD1400900), and The China Scholarship Council (grant No. 201906100164).

\section{Footnote}

Reporting Checklist: The authors have completed the TRIPOD reporting checklist. Available at http://dx.doi. org/10.21037/tp-20-84

Data Sharing Statement: Available at http://dx.doi. org/10.21037/tp-20-84

Conflicts of Interest: All authors have completed the ICMJE uniform disclosure form (available at http://dx.doi. org/10.21037/tp-20-84). The authors have no conflicts of interest to declare.

Ethical Statement: The authors are accountable for all aspects of the work in ensuring that questions related to the accuracy or integrity of any part of the work are appropriately investigated and resolved. The study was performed in accordance with the Declaration of Helsinki (2013 revision) and was approved by the Research Ethics Committee of the Children's Hospital of Fudan University (Ethical code: [2019] 020). Individual consent for this retrospective analysis was waived.

Open Access Statement: This is an Open Access article distributed in accordance with the Creative Commons Attribution-NonCommercial-NoDerivs 4.0 International License (CC BY-NC-ND 4.0), which permits the noncommercial replication and distribution of the article with the strict proviso that no changes or edits are made and the original work is properly cited (including links to both the formal publication through the relevant DOI and the license). See: https://creativecommons.org/licenses/by-nc-nd/4.0/.

\section{References}

1. Bentata Y. Tacrolimus: 20 years of use in adult kidney transplantation. What we should know about its nephrotoxicity. Artif Organs 2020;44:140-52.

2. Andrews LM, de Winter BCM, Cornelissen EAM, et al. A
Population Pharmacokinetic Model Does Not Predict the Optimal Starting Dose of Tacrolimus in Pediatric Renal Transplant Recipients in a Prospective Study: Lessons Learned and Model Improvement. Clin Pharmacokinet 2020;59:591-603.

3. Laub MR, Crow SA, Personett HA, et al. Effects of clotrimazole troches on tacrolimus dosing in heart transplant recipients. Transpl Infect Dis 2018;20:e12979.

4. Miano TA, Flesch JD, Feng R, et al. Early Tacrolimus Concentrations After Lung Transplant Are Predicted by Combined Clinical and Genetic Factors and Associated With Acute Kidney Injury. Clin Pharmacol Ther 2020;107:462-70.

5. Wang D, Chen X, Xu H, et al. Population pharmacokinetics and dosing regimen optimization of tacrolimus in Chinese pediatric hematopoietic stem cell transplantation patients. Xenobiotica 2020;50:178-85.

6. Wang D, Chen X, Li Z. Treatment of patients with systemic-onset juvenile idiopathic arthritis with tacrolimus. Exp Ther Med 2019;17:2305-9.

7. Huang L, Wang J, Yang J, et al. Impact of CYP3A4/5 and $\mathrm{ABCB} 1$ polymorphisms on tacrolimus exposure and response in pediatric primary nephrotic syndrome. Pharmacogenomics 2019;20:1071-83.

8. Kim YH, Shin HY, Kim SM. Long-Term Safety and Efficacy of Tacrolimus in Myasthenia Gravis. Yonsei Med J 2019;60:633-9.

9. Yanagi T, Ushijima K, Koga H, et al. Tacrolimus for ulcerative colitis in children: a multicenter survey in Japan. Intest Res 2019;17:476-85.

10. Wang DD, Lu JM, Li Q, et al. Population pharmacokinetics of tacrolimus in paediatric systemic lupus erythematosus based on real-world study. J Clin Pharm Ther 2018;43:476-83.

11. Hannah J, Casian A, D'Cruz D. Tacrolimus use in lupus nephritis: A systematic review and meta-analysis. Autoimmun Rev 2016;15:93-101.

12. Hanouneh M, Ritchie MM, Ascha M, et al. A review of the utility of tacrolimus in the management of adults with autoimmune hepatitis. Scand J Gastroenterol 2019;54:76-80.

13. Schutte-Nutgen K, Tholking G, Suwelack B, et al. Tacrolimus - Pharmacokinetic Considerations for Clinicians. Curr Drug Metab 2018;19:342-50.

14. Ling Q, Huang H, Han Y, et al. The tacrolimus-induced glucose homeostasis imbalance in terms of the liver: From bench to bedside. Am J Transplant 2020;20:701-13.

15. Llanos-Paez CC, Hennig S, Staatz CE. Population 
pharmacokinetic modelling, Monte Carlo simulation and semi-mechanistic pharmacodynamic modelling as tools to personalize gentamicin therapy. J Antimicrob Chemother 2017;72:639-67.

16. Sime FB, Hahn U, Warner MS, et al. Using Population Pharmacokinetic Modeling and Monte Carlo Simulations To Determine whether Standard Doses of Piperacillin in Piperacillin-Tazobactam Regimens Are Adequate for the Management of Febrile Neutropenia. Antimicrob Agents Chemother 2017;61:e00311-17.

17. Allard M, Puszkiel A, Conti F, et al. Pharmacokinetics and pharmacodynamics of once-daily prolonged-release tacrolimus in liver transplant recipients. Clin Ther 2019;41:882-896.e3.

18. Riff C, Debord J, Monchaud C, et al. Population pharmacokinetic model and Bayesian estimator for 2 tacrolimus formulations in adult liver transplant patients. Br J Clin Pharmacol 2019;85:1740-50.

19. Chen B, Shi HQ, Liu XX, et al. Population pharmacokinetics and Bayesian estimation of tacrolimus exposure in Chinese liver transplant patients. J Clin Pharm Ther 2017;42:679-88.

20. Lu YX, Su QH, Wu KH, et al. A population pharmacokinetic study of tacrolimus in healthy Chinese volunteers and liver transplant patients. Acta Pharmacol Sin 2015;36:281-8.

21. Guy-Viterbo V, Baudet H, Elens L, et al. Influence of donor-recipient CYP3A4/5 genotypes, age and fluconazole on tacrolimus pharmacokinetics in pediatric liver transplantation: a population approach. Pharmacogenomics 2014;15:1207-21.

22. Kassir N, Labbe L, Delaloye JR, et al. Population pharmacokinetics and Bayesian estimation of tacrolimus exposure in paediatric liver transplant recipients. Br J Clin Pharmacol 2014;77:1051-63.

23. Wang DD, Chen X, Fu M, et al. Model extrapolation to a real-world dataset: evaluation of tacrolimus population pharmacokinetics and drug interaction in pediatric liver transplantation patients. Xenobiotica 2020;50:371-9.

24. Wang D, Chen X, Fu M, et al. Pharmacogenomics analysis in Chinese pediatric liver transplantation patients with renal toxicity induced by tacrolimus. Xenobiotica 2020;50:488-93.

25. Yang JW, Liao SS, Zhu LQ, et al. Population pharmacokinetic analysis of tacrolimus early after Chinese pediatric liver transplantation. Int J Clin Pharmacol Ther
2015;53:75-83.

26. Anderson BJ, Holford NH. Mechanism-based concepts of size and maturity in pharmacokinetics. Annu Rev Pharmacol Toxicol 2008;48:303-32.

27. Staatz CE, Tett SE. Clinical pharmacokinetics and pharmacodynamics of tacrolimus in solid organ transplantation. Clin Pharmacokinet 2004;43:623-53.

28. Haufroid V, Mourad M, Van Kerckhove V, et al. The effect of CYP3A5 and MDR1 (ABCB1) polymorphisms on cyclosporine and tacrolimus dose requirements and trough blood levels in stable renal transplant patients. Pharmacogenetics 2004;14:147-54.

29. Wei H, Tao X, Di P, et al. Effects of traditional chinese medicine Wuzhi capsule on pharmacokinetics of tacrolimus in rats. Drug Metab Dispos 2013;41:1398-403.

30. Xin HW, Li Q, Wu XC, et al. Effects of Schisandra sphenanthera extract on the blood concentration of tacrolimus in renal transplant recipients. Eur J Clin Pharmacol 2011;67:1309-11.

31. Xin HW, Wu XC, Li Q, et al. Effects of Schisandra sphenanthera extract on the pharmacokinetics of tacrolimus in healthy volunteers. Br J Clin Pharmacol 2007;64:469-75.

32. Qin XL, Bi HC, Wang CX, et al. Study of the effect of Wuzhi tablet (Schisandra sphenanthera extract) on tacrolimus tissue distribution in rat by liquid chromatography tandem mass spectrometry method. Biomed Chromatogr 2010;24:399-405.

33. Qin XL, Bi HC, Wang XD, et al. Mechanistic understanding of the different effects of Wuzhi Tablet (Schisandra sphenanthera extract) on the absorption and first-pass intestinal and hepatic metabolism of Tacrolimus (FK506). Int J Pharm 2010;389:114-21.

34. Chen X, Wang DD, Xu H, et al. Optimization of initial dosing scheme of tacrolimus in pediatric refractory nephrotic syndrome patients based on CYP3A5 genotype and coadministration with wuzhi-capsule. Xenobiotica 2020;50:606-13.

Cite this article as: Chen $\mathrm{X}$, Wang DD, Xu H, Li ZP. Population pharmacokinetics and pharmacogenomics of tacrolimus in Chinese children receiving a liver transplant: initial dose recommendation. Transl Pediatr 2020;9(5):576-586. doi: $10.21037 /$ tp-20-84 